\title{
Family Medicine and the "New" Opioid Epidemic
}

\author{
Mark S. Johnson, MD, MPH
}

(J Am Board Fam Med 2020;33:1-3.)

The opioid crisis is America's Ebola. Often fatal, complicated, with multiple ramifications that go beyond just medicine to the core of our culture. Clinicians' response to pharma promotions and pain as the fifth vital sign is part of that culture. The complicity of pharma is being adjudicated in the courts. Solutions to this problem have been evolving quickly as a new urgency has erupted in response to the magnitude of the death rates. And as we explore solutions to this "new" epidemic, we see that solutions for one thing can cause problems for another. In this example, we find that those who believe that they need and thus should have access to chronic opioids are having trouble getting them. We also find that many of these patients have not had appropriate trials to reduce dosages or try alternate modes of therapy. Furthermore, the current climate has increased the fear that clinicians feel when "confronted" by a patient in pain. We need research to create the evidence that will yield best practices.

\section{Family Medicine Care}

The involvement of family physicians in the care of these patients has escalated by necessity. Practitioners in small towns around the country began to see their patients die. They had no idea that John or Jill was addicted. Many did not know that the prevalence of opioids was increasing exponentially in their communities. This special issue of the fournal of American Board of Family Medicine ( 7 ABFM) provides a glimpse into this complex problem. A major focus of care to those with opioid-use disorder

\footnotetext{
Funding: none.

Conflict of interest: The author is an Editorial Board member of the $7 A B F M$.

Corresponding author: Mark S. Johnson, MD, MPH, Department of Community and Family Medicine, Howard University College of Medicine, 520 W Street NW, Washington, DC 20059 (E-mail: mark.johnson@Howard.edu).
}

(OUD) is medication-assisted therapy (MAT). The role of family medicine in MAT is evolving. Several articles in this issue describe these roles.

Peterson et $\mathrm{al}^{1}$ used the unique database of those taking the American Board of Family Medicine (ABFM) certification examination to elucidate important variables with a $100 \%$ response rate. They found that $5.9 \%$ of family physicians reported prescribing buprenorphine. Family physicians who worked in a Federally Qualified Health Center (FQHC), those in solo practice, or who had a mental health professional working with them were more likely to prescribe. In a policy brief, Peterson and his team ${ }^{2}$ report that graduating residents and early career family physicians are leading the growth of new prescribers, so a bigger effort will be required from midcareer and older family physicians if we are going to substantially increase those ready to prescribe. This is more important when one considers that many of those who do get the waiver will never actually prescribe, because of real and perceived barriers. Abraham et al, ${ }^{3}$ using Medicare data, found that while family physicians and internists were the main prescribers of buprenorphine, only $2.7 \%$ and $2.0 \%$ were prescribing, respectively. Factors considered to increase likelihood of prescribing were male gender, northeast location, DO degree, US undergraduate training, more years in practice, and more dual eligible patients.

A number of articles examine facets of opioid prescribing. Sokol's team ${ }^{4}$ used 2 models of change to promote practice improvement for care to both those with OUD and those who are prescribed opioids. Articles by van Eeghen et $\mathrm{al}^{5}$ and Breeden et $\mathrm{al}^{6}$ use best practices to improve adherence to opioid prescribing guidelines. The article by Raad et $\mathrm{al}^{7}$ shows that the prescribing of opioids for low-back pain declined from 2011 to 2016. However, there were still large differences in prescrib- 
ing by state. Jerant et $\mathrm{al}^{8}$ looked at patient satisfaction related to opioids and found that 6 or more opioid prescriptions per year was associated with higher patient satisfaction. Diiulio et $\mathrm{al}^{9}$ used qualitative methods to examine reasons for changing existing chronic pain management plans.

Magnan et $\mathrm{al}^{10}$ looked at patient satisfaction related to having a denial from the doctor. Although the denial of pain medication was one of the reasons considered, they did not offer separate data to understand this possible contributing factor. However, they did point out the importance of continuity. Two articles discuss nonopioid substances. Redinger et $\mathrm{al}^{11}$ propose an ethical framework for medicinal marijuana that helps physicians make decisions based on their beliefs within the current legal restraints. Loskutova et $\mathrm{al}^{12}$ conducted a survey of family physicians and college health professionals to determine practice patterns regarding stimulants and the growing concerns about stimulant diversion.

Other important topics are covered in this issue as well. The team lead by Purkable ${ }^{13}$ conducted an intervention to promote discussions of quality of life goals. The associations between education level, depression care, and shared decision making is explored in the article by Brodney et al. ${ }^{14}$ Crego et $\mathrm{al}^{15}$ examined the relationship between comanagement and hydroxyurea utilization in sickle-cell patients covered by Medicaid. A qualitative analysis by Moerenhout et $\mathrm{al}^{16}$ explored ethical questions posed by shared electronic medical records. Johansen et $\mathrm{al}^{17}$ used the Medical Expenditure Panel Survey (MEPS) database to determine the frequency and type of medication combinations used for hypertension.

\section{Need for Future Research}

Those of us who have been practicing in urban centers know that this "epidemic" is not new. It may be different because now those affected are more likely to be white and young. It is also different because those so afflicted are more likely to be seen as ill instead of having a moral failing. For our response to the current need to be successful, it will take more clinician person power and more research. This research need cries out for interdisciplinary collaborations of all types. We need more research on the genomic susceptibility and the genomics of treatment. ${ }^{18} \mathrm{We}$ need research with communication experts and anthropologists about the optimizing the messaging from clinicians to achieve the desired outcomes. We need research with social workers and other providers to determine the contribution of case management models to promote adherence. Research is needed with behavioral scientists with particular attention to the fact the many of our OUD patients also have comorbid psychiatric diagnoses. And as suggested by the Farrar article, ${ }^{19}$ we need more economic analyses to determine feasibility and outcomes from different care designs.

\section{Need for Qualified Family Physicians}

A major problem is a shortage of family physicians who can act as clinical mentors to those who have completed waiver training. Increasing the number of family physicians who complete addiction medicine fellowships (and increasing the number of departments who sponsor them) will improve this situation. Another strategy is using Extension for Community Healthcare Outcomes (ECHO) methods for telementoring. ${ }^{20}$ Finally, advocacy deserves to be mentioned regarding the emergence of OUD as a rising public health problem. We must inoculate our nation to protect our citizens from the spread of addiction and reduce the social conditions that predispose us to OUD and that result from OUD. Family physicians could and should advocate to remove barriers to care with government, insurance companies, and law enforcement.

To see this article online, please go to: http://jabfm.org/content/ 33/1/1.full.

\section{References}

1. Peterson LE, Morgan ZJ, Borders TF. Practice predictors of buprenorphine prescribing by family physicians. J Am Board Fam Med 2020;33:118-123.

2. Peterson LE, Morgan ZJ, Eden AR. Early-career and graduating physicians more likely to prescribe buprenorphine. J Am Board Fam Med 2020;33:7-8.

3. Abraham R, Wilkinson E, Jabbarpour Y, Petterson $\mathrm{S}$, Bazemore A. Characteristics of office-based buprenorphine prescribers for Medicare patients. J Am Board Fam Med 2020;33:9-16.

4. Sokol R, Schuman-Olivier Z, Batalden M, Sullivan L, Shaughnessy AF. A change management case study for safe opioid prescribing and opioid use disorder treatment. J Am Board Fam Med 2020;33: $129-137$.

5. van Eeghen C, Kennedy AG, Pasanen ME, MacLean CD. A new quality improvement toolkit to improve 
opioid prescribing in primary care. J Am Board Fam Med 2020;33:17-26.

6. Breeden MA, Jacobs CK, Witthaus M, et al. Prescribing patterns and use of risk-reduction tools after implementing an opioid-prescribing protocol. J Am Board Fam Med 2020;33:27-33.

7. Raad M, Pakpoor J, Harris A, et al. Opioid prescriptions for new low back pain: trends and variability by state. J Am Board Fam Med 2020;33:138-142.

8. Jerant A, Agnoli A, Franks P. Satisfaction with health care among prescription opioid recipients. J Am Board Fam Med 2020;33:34-41.

9. Diiulio J, Militello L, Andraka-Christou BT, et al. Factors that influence changes to existing chronic pain management plans. J Am Board Fam Med 2020; $33: 42-50$.

10. Magnan EM, Franks P, Jerant A, Kravitz RL, Fenton JJ. When physicians say no: predictors of request denial and subsequent patient satisfaction. J Am Board Fam Med 2020;33:51-58.

11. Redinger M, Fledderman N, Crutchfield P. An ethical framework to manage patient requests for medical marijuana. J Am Board Fam Med 2020;33:147151.

12. Loskutova N, Waterman J, Callen E, Staton EW, Bullard E, Shields J. Knowledge, attitudes and practice patterns of health professionals toward medical and non-medical stimulant use by young adults. J Am Board Fam Med 2020;33:59-70.
13. Purkaple BA, Nagykaldi ZJ, Allahyar A, Todd R, Mold JW. Physicians' response to patients' quality-of-life goals. J Am Board Fam Med 2020;33: 71-79.

14. Brodney S, Fowler FJ Jr, Stringfellow V, Valentine KD, Barry MJ. National survey of decision-making for antidepressants and educational level. J Am Board Fam Med 2020;33:80-90.

15. Crego N, Douglas C, Bonnabeau E, et al. Sickle cell disease co-management, health care utilization and hydroxyurea use. J Am Board Fam Med 2020;33:91-105.

16. Moerenhout T, Fischer GS, Saelaert M, De Sutter A, Provoost V, Devisch I. Primary care physicians' perspectives on the ethical impact of the electronic medical record. J Am Board Fam Med 2020;33:106-117.

17. Johansen ME, Yun J, Griggs JM, Jackson EA, Richardson CR. Anti-hypertensive medication combinations in the United States. J Am Board Fam Med 2020;33:143-146.

18. Ettienne EB, Ofoegbu A, Maneno MK, et al. Pharmacogenomics and OUD: clinical decision support in an African American cohort. J Natl Med Assoc. 2019 [Epub ahead of print].

19. Farrar M, White Z, Hulkower S, Fagan EB, Gilmore Wilson C. A financial model for team-based opioid use disorder treatment. J Am Board Fam Med 2020; $33: 124-128$

20. University of New Mexico School of Medicine. Project ECHO. Available from: https://echo.unm.edu/. Accessed November 21, 2019. 